University of Wollongong

Research Online

Australian Institute for Innovative Materials -

Papers

Australian Institute for Innovative Materials

$1-1-2017$

Nitrogen-Doped Nanoporous Carbon Membranes with Co/CoP Janus-Type Nanocrystals as Hydrogen Evolution Electrode in Both Acidic and Alkaline Environments

\author{
Hong Wang \\ King Abdullah University of Science and Technology \\ Shixiong Min \\ Beifang University of Nationalities \\ Qiang Wang \\ Chinese Academy Of Sciences \\ Debao Li \\ Chinese Academy Of Sciences \\ Gilberto Casillas \\ University of Wollongong, gilberto@uow.edu.au
}

See next page for additional authors

Follow this and additional works at: https://ro.uow.edu.au/aiimpapers

Part of the Engineering Commons, and the Physical Sciences and Mathematics Commons

Research Online is the open access institutional repository for the University of Wollongong. For further information contact the UOW Library: research-pubs@uow.edu.au 


\title{
Nitrogen-Doped Nanoporous Carbon Membranes with Co/CoP Janus-Type Nanocrystals as Hydrogen Evolution Electrode in Both Acidic and Alkaline Environments
}

\author{
Abstract \\ Self-supported electrocatalysts being generated and employed directly as electrodes for energy \\ conversion has been intensively pursued in the fields of materials chemistry and energy. Herein, we report \\ a synthetic strategy to prepare freestanding hierarchically structured, nitrogen-doped nanoporous \\ graphitic carbon membranes functionalized with Janus-type Co/CoP nanocrystals (termed as HNDCM- \\ Co/CoP), which were successfully applied as a highly efficient, binder-free electrode in the hydrogen \\ evolution reaction (HER). Benefited from multiple structural merits, such as a high degree of \\ graphitization, three-dimensionally interconnected micro/meso/macropores, uniform nitrogen doping, \\ well-dispersed $\mathrm{Co} / \mathrm{CoP}$ nanocrystals, as well as the confinement effect of the thin carbon layer on the \\ nanocrystals, HNDCM-Co/CoP exhibited superior electrocatalytic activity and long-term operation stability \\ for HER under both acidic and alkaline conditions. As a proof-of-concept of practical usage, a $5.6 \mathrm{~cm} \times 4$ \\ $\mathrm{cm} \times 60 \mu \mathrm{m}$ macroscopic piece of HNDCM-Co/CoP was prepared in our laboratory. Driven by a solar cell, \\ electroreduction of water in alkaline conditions ( $\mathrm{pH} 14)$ was performed, and $\mathrm{H} 2$ was produced at a rate of \\ $16 \mathrm{~mL} / \mathrm{min}$, demonstrating its potential as real-life energy conversion systems. \\ Disciplines \\ Engineering | Physical Sciences and Mathematics

\section{Publication Details} \\ Wang, H., Min, S., Wang, Q., Li, D., Casillas, G., Ma, C., Li, Y., Liu, Z., Li, L., Yuan, J., Antonietti, M. \& Wu, T. \\ (2017). Nitrogen-Doped Nanoporous Carbon Membranes with Co/CoP Janus-Type Nanocrystals as \\ Hydrogen Evolution Electrode in Both Acidic and Alkaline Environments. ACS Nano, 11 (4), 4358-4364.

\section{Authors} \\ Hong Wang, Shixiong Min, Qiang Wang, Debao Li, Gilberto Casillas, Chun Ma, Yangyang Li, Zhixiong Liu, \\ Lain Li, Jiayin Yuan, Markus Antonietti, and Tom Wu
}




\section{Nitrogen-doped Nanoporous Carbon Membranes}

\section{with $\mathrm{Co} / \mathrm{CoP}$ Janus-type Nanocrystals as Hydrogen}

\section{Evolution Electrode in Both Acid and Alkaline}

\section{Environment}

Hong Wang ", Shixiong Min ${ }^{\#,}$ Qiang Wang ${ }^{\S}$, Debao Li ${ }^{\S}$, Gilberto Casillas ${ }^{\perp}$, Chun Ma ${ }^{\dagger}$ Yangyang Li', Zhixiong Liu', Lain-Jong Lit, Jiayin Yuan ${ }^{\| * *}$, Markus Antonietti", Tom Wu ${ }^{\dagger *}$

Thysical Science and Engineering Division, King Abdullah University of Science \& Technology (KAUST), Thuwal, 23955-6900, Saudi Arabia

"School of Chemistry and Chemical Engineering, Beifang University of Nationalities, Yinchuan, Ningxia, China

${ }^{\S}$ State Key Laboratory of Coal Conversion, Institute of Coal Chemistry, the Chinese Academy of Sciences, Taiyuan 030001, China

${ }^{\perp}$ UOW Electron Microscopy Centre, University of Wollongong, Wollongong, New South Wales 2500, Australia

"Department of colloidal chemistry, Max Planck Institute of Colloids and Interfaces, 14476

Potsdam, Germany

"Department of Chemistry and Biomolecular Science, Clarkson University, 13699, USA 
KEYWORDS: Carbon membrane, N-doping, Hierarchical architecture, Electrocatalyst, Water splitting

ABSTRACT. Self-supported electrocatalysts being generated and employed directly as electrode for energy conversion has been intensively pursued in the fields of materials chemistry and energy. Herein, we report a synthetic strategy to prepare freestanding hierarchically structured, nitrogen-doped nanoporous graphitic carbon membranes functionalized with Janus-type Co/CoP nanocrystals (termed as HNDCM-Co/CoP), which were successfully applied as a highlyefficient, binder-free electrode in hydrogen evolution reaction (HER). Benefited from multiple structural merits, such as high degree of graphitization, three-dimensionally interconnected micro-/meso-/macropores, uniform nitrogen-doping, well-dispersed $\mathrm{Co} / \mathrm{CoP}$ nanocrystals as well as the confinement effect of the thin carbon layer on the nanocrystals, HNDCM-Co/CoP exhibited superior electrocatalytic activity and long-term operation stability for HER under both acid and alkaline conditions. As a proof-of-concept of practical usage, a macroscopic piece of $\mathrm{HNDCM}-\mathrm{Co} / \mathrm{CoP}$ of $5.6 \mathrm{~cm} \times 4 \mathrm{~cm} \times 60 \mu \mathrm{m}$ in size was prepared in our laboratory. Driven by a solar cell, electroreduction of water in alkaline condition ( $\mathrm{pH}$ 14) was performed, and $\mathrm{H}_{2}$ has been produced at a rate of $16 \mathrm{ml} / \mathrm{min}$, demonstrating its potential as real-life energy conversion systems.

Hydrogen is a clean, renewable energy carrier and has been actively pursued as an alternative to fossil fuels..$^{1-3}$ Sustainable production of hydrogen from water splitting is an appealing solution yet requires highly efficient, long-term stable electrocatalyst. ${ }^{4,5}$ As a benchmark electrocatalyst, platinum is sufficiently active in hydrogen evolution reaction (HER), ${ }^{6}$ but suffers from high cost and scarcity. As technological breakthroughs, a variety of non-noble metal catalysts, e.g. $\mathrm{Ni}_{2} \mathrm{P}$, 
$\mathrm{Mo}_{2} \mathrm{C} / \mathrm{MoB},{ }^{8} \mathrm{CoO}_{\mathrm{x}},{ }^{9} \mathrm{CoPS},{ }^{10} \mathrm{MoS}_{2}$ and its hybrids, ${ }^{11-13} \mathrm{CoP} / \mathrm{CNTs},{ }^{14}$ alloys,${ }^{15}$ and $\mathrm{CoSe}_{2}$ and its carbon hybrids, ${ }^{16,17}$ just to name a few, have been explored for HER. Among these systems, carbon-based hybrids were found to outperform pristine metal ones due to the following factors that are still under debate: i) chemical and electrical coupling effects (charge transfer, heterojunction, etc.) between metallic electrocatalyst and conductive carbon; ${ }^{18,19}$ ii) better accessible active centers of metal species endowed by the conductive porous carbon scaffold. ${ }^{14,20}$ The choice of carbon nanostructures is in this regard critical for design and engineering of HER electrocatalyst, and usually powdrous carbon nanostructures such as reduced graphene oxide, ${ }^{21-25}$ carbon nanotubes, ${ }^{14,26} \mathrm{~N}$-doped carbons, ${ }^{9,27}$ are mostly applied in the field. In spite of their favorable efficiency in $\mathrm{H}_{2}$ generation, device-wise the powderous electrocatalysts have to be engineered into electrodes of defined shape usually via the usage of a polymer binder, such as Nafion or polyvinylidene fluoride. The use of binders is a mature processing practice in industry for decades, but their presence leads to multiple undesirable effects, including reduced cell conductivity, weak polymer/carbon/metal heterojunction, and blocking of the active centers or restricted diffusion that leads to reduced catalytic activity. Additionally, the side reactions of polymer binders during the electrochemical process are a rising concern. ${ }^{28}$

The problem of electrode integrity is solved by applying a macroscopic carbon membrane supported electrocatalyst as a binder-free electrodes for HER, in which the synthesis of highquality porous carbon membranes is the key step. It is well-recognized that the carbon membrane design should entail a hierarchical pore architecture over broad length scales from micro- to meso- to macropores. The macropores afford rapid mass transport for the fluid and gas phase, and simultaneously the micro-/mesopores intrinsically contribute to a large specific surface area that provides enhanced reaction capacity for the heterogeneous reactions. In this context, the 
electrocatalyst reaches an optimized balance between activity and diffusion kinetics. ${ }^{29}$ Equally important, heteroatoms, such as nitrogen, when covalently bound in the carbon network, are able to tailor and improve material properties of carbons such as conductivity, chemical inertness and basicity, which are beneficial to their catalytic function in HER, ${ }^{22,30,31}$ These desirable features raise structural and synthetic complexity and challenge the design of carbon membrane-derived electrocatalyst for HER.

So far, most HER electrocatalysts are known to work efficiently under strongly acidic condition, simply because the large amount of $\mathrm{H}^{+}$facilitates the HER process for thermodynamic and kinetic reasons ${ }^{32}$ On the other hand, alkaline conditions are more challenging to produce $\mathrm{H}_{2}$ by electrolysis, as the system inherently suffers from high overpotentials and instability. ${ }^{33}$ Nevertheless, generating hydrogen by electrolysis in alkaline media has been utilized for decades in industry, ${ }^{34,35}$ as it offers high purity hydrogen and more importantly, the alkaline media simplifies the oxygen production side and causes less stability problems associated with the catalyst. Therefore, design of active, durable and low-cost electrocatalysts that can work well in alkaline media is highly desirable from the viewpoint of practical applications.

Herein, we report the synthesis of freestanding, hierarchically porous, nitrogen-doped graphitic carbon membranes loaded with Janus-type Co/CoP nanocrystals (termed HNDCM$\mathrm{Co} / \mathrm{CoP}$ ), which demonstrate high activity towards HER in both acid and alkaline range. Electrochemical measurements on the HNDCM-Co/CoP catalyst showed a low overpotential of $135 \mathrm{mV}$ and $138 \mathrm{mV}$ at $10 \mathrm{~mA} \mathrm{~cm}-2$ in acid and alkaline conditions, respectively, which is accompanied by long-term durability over $20 \mathrm{~h}$ of HER operation in both acid and alkaline media. 
The synthetic route towards the targeted HNDCM-Co/CoP for HER electrocatalysis is displayed in Figure 1, in which a nanoporous polymer membrane (termed as NPPM) built up via interpolyelectrolyte complexation was used as a sacrificial soft template (Figure 1a, 1c and Figure S1) (see experimental section). A key feature of polyelectrolyte complexes is their capability to bind and immobilize metal ions, salts, and charged nanoparticles, ${ }^{36}$ which remarkably simplifies functionalization of the NPPM with metal nanoparticles. Here Co salt was chosen because, besides its relatively high abundance in nature, it has been theoretically demonstrated that some Co surfaces have a low energy barrier for $\mathrm{H}$ adsorption, and thus Cobased electrocatalysts hold a great promise in $\mathrm{HER},{ }^{37} \mathrm{Co}^{2+}$ ions were immobilized in the NPPM by refluxing the as-prepared NPPM in an aqueous solution of cobalt acetate for $24 \mathrm{~h}$. After rinsing with deionized water and drying, the NPPM-cobalt acetate precursor was pyrolyzed at $1000{ }^{\circ} \mathrm{C}$ under $\mathrm{N}_{2}$ flow to form Co nanoparticles functionalized carbon membrane, termed HNDCM-Co, the structure of which was confirmed by XRD and high-resolution transmission electron microscopy (HRTEM) characterizations (Figure S2, S3). The final HNDCM-Co/CoP (Figure 1b, 1d) with a shiny black color was obtained by phosphatization of HNDCM-Co using $\mathrm{NaH}_{2} \mathrm{PO}_{4}$ at $350{ }^{\circ} \mathrm{C}$ for $3 \mathrm{~h}$ under $\mathrm{N}_{2}$ flow. 
a)

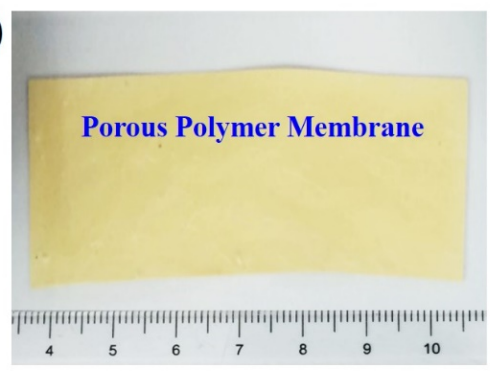

c)

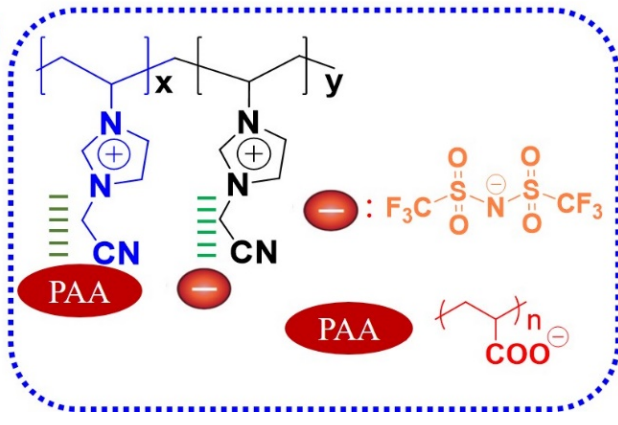

b)

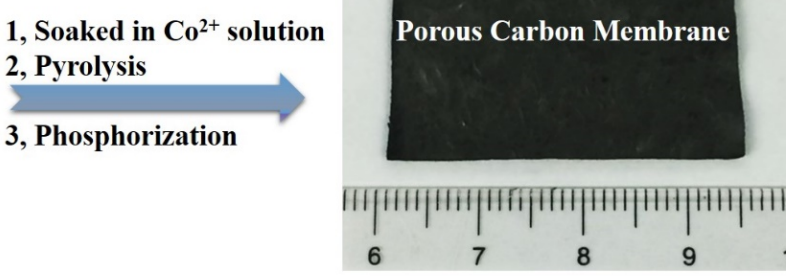

d)

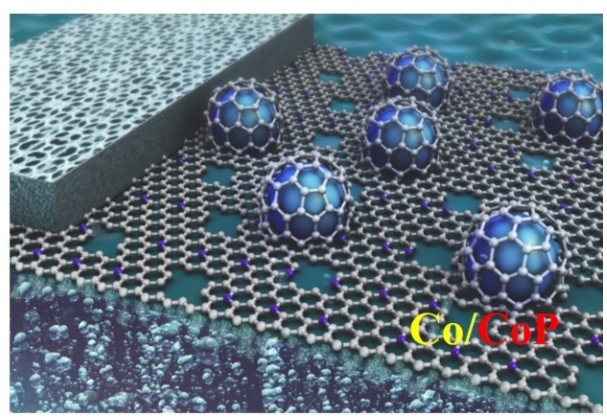

Figure 1, Synthetic procedure of hierarchically porous, nitrogen-doped graphitic carbon membranes loaded with Janus-type Co/CoP nanocrystals (HNDCM-Co/CoP). (a, b) Photographs of a freestanding NPPM of $7 \times 3 \mathrm{~cm}^{2}$, and a corresponding freestanding HNDCM-Co/CoP of 3.4 x $2 \mathrm{~cm}^{2}$ in size. (c, d) the schematic presentation of the NPPM structure and the HNDCM$\mathrm{Co} / \mathrm{CoP}$.

\section{RESULTS AND DISCUSSION}

Figure 2a shows the SEM image of a cross-section of the HNDCM-Co/CoP hybrid membrane, in which the typical gradient of macropore size is clearly observable. The average macropore size in zone I, zone II, and zone III are $1.6 \mu \mathrm{m}, 850 \mathrm{~nm}$ and $550 \mathrm{~nm}$, respectively, i.e. the pore size gradually decreases from top to bottom. The three dimensionally interconnected cellular architecture can be clearly recognized in the enlarged SEM image in Figure 2b. On the pore walls, plenty of bright dots, i.e. the metal nanocrystals, are uniformly dispersed (denoted by red arrows, Figure 2c). The transmission electron microscopy (TEM) image in Figure S4 further discloses the porous structure of the HNDCM-Co/CoP and confirms again the uniform 
distribution of $\mathrm{Co} / \mathrm{CoP}$ nanocrystals of $10 \sim 40 \mathrm{~nm}$ in size throughout the entire membrane. Energy-filtered transmission electron microscopy mappings for C, N, Co and P (Figure 2d) indicate a uniform distribution of $\mathrm{N}$ in the carbon matrix, which is expected due to in situ molecular doping of HNDCM with $\mathrm{N}_{.38}^{38}$ It should be noted that P only exists in the regions of Co, indicating that the low temperature $\left(350^{\circ} \mathrm{C}\right)$ phosphatization of $\mathrm{HNDCM}-\mathrm{Co}$ using $\mathrm{NaH}_{2} \mathrm{PO}_{4}$ did not lead to the formation of P-doped carbon. Surprisingly, after merging of elemental mappings of $\mathrm{Co}$ and $\mathrm{P}$, it was found that majority of nanocrystals were composed of $\mathrm{Co} / \mathrm{CoP}$ Janus-type nanostructures (Figure 2e). The phases of $\mathrm{Co}$ and $\mathrm{CoP}$ were further confirmed by using atomic high-angle annular dark-field scanning transmission electron microscopy (HAADF-STEM, Figure 2f, 2g). In order to understand the formation mechanism of Janus-type structure of $\mathrm{Co} / \mathrm{CoP}$, a single $\mathrm{Co} / \mathrm{CoP}$ Janus-type nanocrystal was analyzed by HRTEM (Figure S5). It was found that the Co region is protected by a few $\mathrm{nm}$ thin graphitic layer, while the $\mathrm{CoP}$ region is exposed to surrounding. Therefore, it is reasonable to conceive that the phosphatization reaction first occurred on the exposed surfaces of Co nanoparticles, while the graphitic carbon protected Co is difficult to be phosphatized, thus forming such a Janus-type structure of $\mathrm{Co} / \mathrm{CoP}$.

The phase of HNDCM-Co/CoP was further confirmed by X-ray diffraction (XRD) and X-ray photoelectron spectroscopy (XPS), as shown in Figure S6. The total Co content was $42.8 \mathrm{mg} / \mathrm{g}$, as detected by inductively coupled plasma-atomic emission spectra. The relative content of Co and $\mathrm{CoP}$ in Janus-type $\mathrm{Co} / \mathrm{CoP}$ nanocrystals can be calculated from the XPS spectra (Figure S6c) as $13.3 \mathrm{mg} / \mathrm{g}$ and $29.5 \mathrm{mg} / \mathrm{g}$, respectively. Furthermore, the HRTEM image in Figure S7 shows that a disordered graphitic character is maintained throughout the entire porous membrane. The well-developed graphitic carbon membrane endows the HNDCM-Co/CoP with favorably high conductivity of $51 \mathrm{~S} \mathrm{~cm}^{-2}$ at $25^{\circ} \mathrm{C}$ (Figure S8). The high conductivity of HNCM- 
$\mathrm{Co} / \mathrm{CoP}$ favors fast charge transport, a mandatory requirement for efficient electrocatalysis. The content of $\mathrm{N}$ in NHDCM-Co/CoP is $5.4 \mathrm{wt} \%$, as determined by elemental analysis. All of these results point out that Janus-type $\mathrm{Co} / \mathrm{CoP}$ nanoalloy crystals were formed and embedded in the $\mathrm{N}$ doped porous carbon membrane via the low-temperature phosphatization of HNDCM-Co. The functionalization of transition-metal nanocomposite-based electrocatalysts, improving the compatibility of these electrocatalysts with electrolytes, is currently one of the most important research topics in the field of electrocatalysis.$^{39}$ Mott-Schottky catalysts, made of metal-semiconductor heterojunctions, have been recently applied to dehydrogenation, artificial photosynthesis, and eletrocatalysis. ${ }^{40,41}$ It is a consensus that the Mott-Schottky effect at the metal-semiconductor interfaces of Janus nanoparticles can dramatically promote the final performance and stability owing to possible synergetic effects and enhanced electron transfer efficiency at the interface between different components (Figure S9). In addition, the close contact between metal (Co in our case) and $\mathrm{N}$-doped carbon is effective in producing a rectifying effect (Figure S10), which can polarize/activate the interface and improve the final catalytic performance. ${ }^{39}$ 

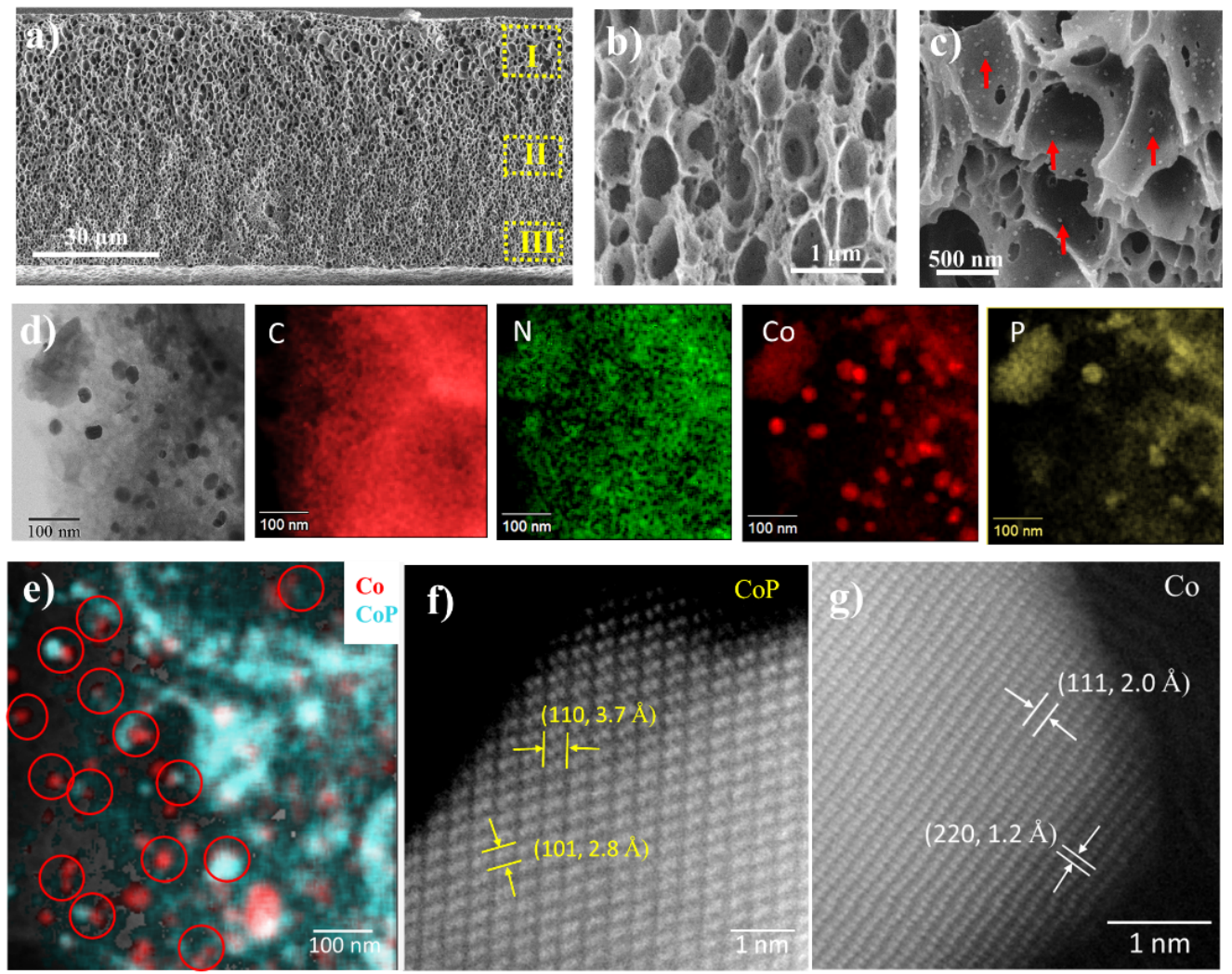

Figure 2. (a-c), Overview and close view of the cross-sectional SEM images of HNDCMCo/CoP. (d) Energy-filtered transmission electron microscopy mappings for C, N, Co and P. (e) Merged elemental mappings of Co and P. Red circles indicate Janus-type nanostructures of $\mathrm{Co} / \mathrm{CoP}$. Also shown are the HAADF-STEM images of (f) CoP and (g) Co phases in Janus-type nanocrystals.

Specific surface area plays an essential role in optimizing catalytic activity of heterogeneous catalysts. The Brunauer-Emmett-Teller (BET) specific surface area of HNDCM-Co/CoP was determined by nitrogen gas sorption to be $589 \mathrm{~m}^{2} / \mathrm{g}$ (Figure 3a). The sharp increase of BET at low pressures $\left(\mathrm{P} / \mathrm{P}_{0}<0.05\right)$ is due to the nitrogen filling in micropores below $2 \mathrm{~nm}$, which is quantified by the density functional theory (DFT) pore size distribution curves (Figure 3b) derived from the $\mathrm{N}_{2}$ adsorption branches. The obvious hysteresis above $\mathrm{P} / \mathrm{P}_{0} \sim 0.5$ is indicative of 
the existence of mesopores. The pore volumes of the micropores and mesopores were 0.07 and $0.58 \mathrm{~cm}^{3} \mathrm{~g}^{-1}$, respectively. It is clear that the porous carbon membrane features not only a gradient in the macropore size distribution along its cross-section, but is also simultaneously rich in micro- and mesopores. As previously mentioned, the large macropores provide transport highways while the micro- and mesopores offer the necessary large specific surface areas bearing active sites for the heterogeneous reactions. It should be noted that this pore texture in the porous carbon membrane is obtained in a single carbonization step without any postsynthesis activation treatment. Owing to the high conductivity, satisfactory BET surface area, hierarchical pore architecture as well as evenly dispersed $\mathrm{Co} / \mathrm{CoP}$ nanocrystals, HNDCM$\mathrm{Co} / \mathrm{CoP}$ is well suited for many electrochemical processes, and it will be exemplified in the model case of water splitting as discussed below.
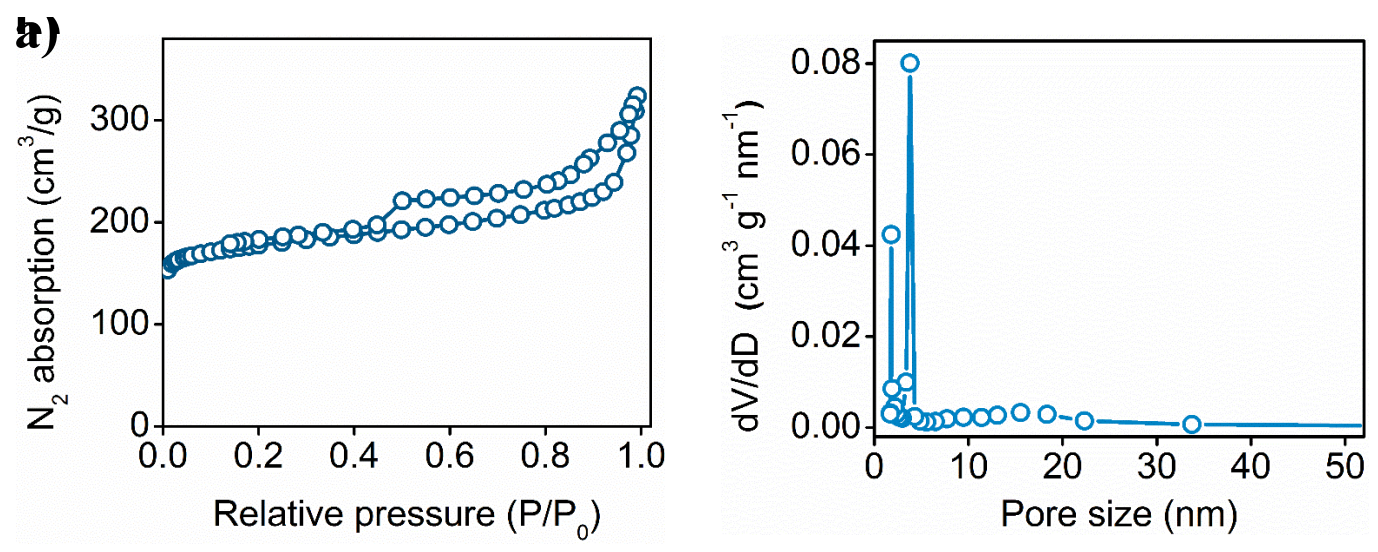

Figure 3. (a) $\mathrm{N}_{2}$ absorption-desorption isotherms and (b) corresponding pore size distribution of HNDCM-Co/CoP.

The HER activity of HNDCM-Co/CoP was evaluated using a standard three-electrode electrochemical cell in both acid and alkaline conditions and was compared with the metal-free carbon membrane HNDCM, and only Co nanoparticle-functionalized carbon membrane 
HNDCM-Co. It is noted that the size and thickness of the three electrocatalysts as well as the membranes textures are almost equal. All HER data has been corrected based on the impedance spectroscopy measurements, as shown in Figure 4. At $10 \mathrm{~mA} / \mathrm{cm}^{2}$, HNDCM and HNDCM-Co exhibited overpotentials of 823 and $247 \mathrm{mV}$, respectively. Under the exact same condition, HNDCM-Co/CoP showed the lowest overpotential of $138 \mathrm{mV}$, which is in fact one of the best non-noble-metal electrocatalysts reported so far for HER (Figure 4a) (Table S1). In a basic environment, i.e., in $1 \mathrm{M} \mathrm{KOH} \mathrm{(pH} \mathrm{14),} \mathrm{the} \mathrm{LSV} \mathrm{curves} \mathrm{(Figure} 4 \mathbf{b}$ ) present overpotentials of 723 and $216 \mathrm{mV}$, respectively, for HNDCM and HNDCM-Co at $10 \mathrm{~mA} / \mathrm{cm}^{2}$, which are slightly lower than that in acid condition. It indicates that alkaline conditions are more favorable for Ndoped carbon-based samples than acidic conditions, also for the HER operation. HNDCM$\mathrm{Co} / \mathrm{CoP}$ requires an overpotential as low as $135 \mathrm{mV}$, close to that in acidic condition. It should be noted that the 'noise' in LSV curves for HER in both of acid and alkaline conditions were generated by perturbations in our membrane catalyst due to the release of large amounts of $\mathrm{H}_{2}$ bubbles that were produced at higher overpotentials. Thus far, there have been only a few electrocatalysts active in both acid and alkaline conditions, due to the incompatibility of the activity of the same electrocatalyst operating in the same $\mathrm{pH}$ region, ${ }^{42,43}$ The activities for HER in alkaline are usually about $2 \sim 3$ orders of magnitude lower than those in acidic medium. ${ }^{44}$ In our case, the excellent HER activity of HNDCM-Co/CoP in alkaline condition can be potentially attributed to the multiple heterojunctions, i.e. the support interaction with the $\mathrm{N}$-doped carbon as well as the bi-phasic character of Co and CoP in the Janus nanocrystals.

Tafel plots were used to elucidate the electron-transfer kinetics. The linear portions of the Tafel plots (Figure 4c) are fitted to the Tafel equation: $\eta=b \log j+a$, where $j$ is the current density and $b$ is the Tafel slope. The Tafel slopes of HNDCM-Co/CoP are determined to be 
approximately 64 and $66 \mathrm{mV} \mathrm{dec}{ }^{-1}$ in $0.5 \mathrm{M} \mathrm{H}_{2} \mathrm{SO}_{4}$ and $1 \mathrm{M} \mathrm{KOH}$, respectively. This result suggests that the HER over HNDCM-Co/CoP followed a Volmer-Heyrovsky mechanism in both acid and alkaline conditions, and the electrochemical desorption is the rate-limiting step. ${ }^{14,45}$

Additionally, stability of electrocatalysts in practical operation conditions is a key parameter. We investigated the long-term electro-chemical stability of HNDCM-Co/CoP for HER in both acid and alkaline conditions (Figure 4d), and no decay was detected during continuous operation of $20 \mathrm{~h}$. Meanwhile, the cyclic voltammetry (CV) durability tests of the HNDCM-Co/CoP electrodes for HER in both of acid and alkaline conditions were carried out, and as shown in Figure S11, the HNDCM-Co/CoP electrodes exhibited negligible loss of activity after $1000 \mathrm{CV}$ sweeps. In fact, N-doping leads to the basicity of the HNDCM-Co/CoP, which could improve the electrochemical stability and resistance against oxidation by modifying the electronic band structure of the graphitic carbons ${ }^{46,47}$ Furthermore, the integrated porous membrane structure (binder-free) and probably the confinement effect of the thin carbon layer on the nanocrystals help endow HNDCM-Co/CoP with excellent stability. 

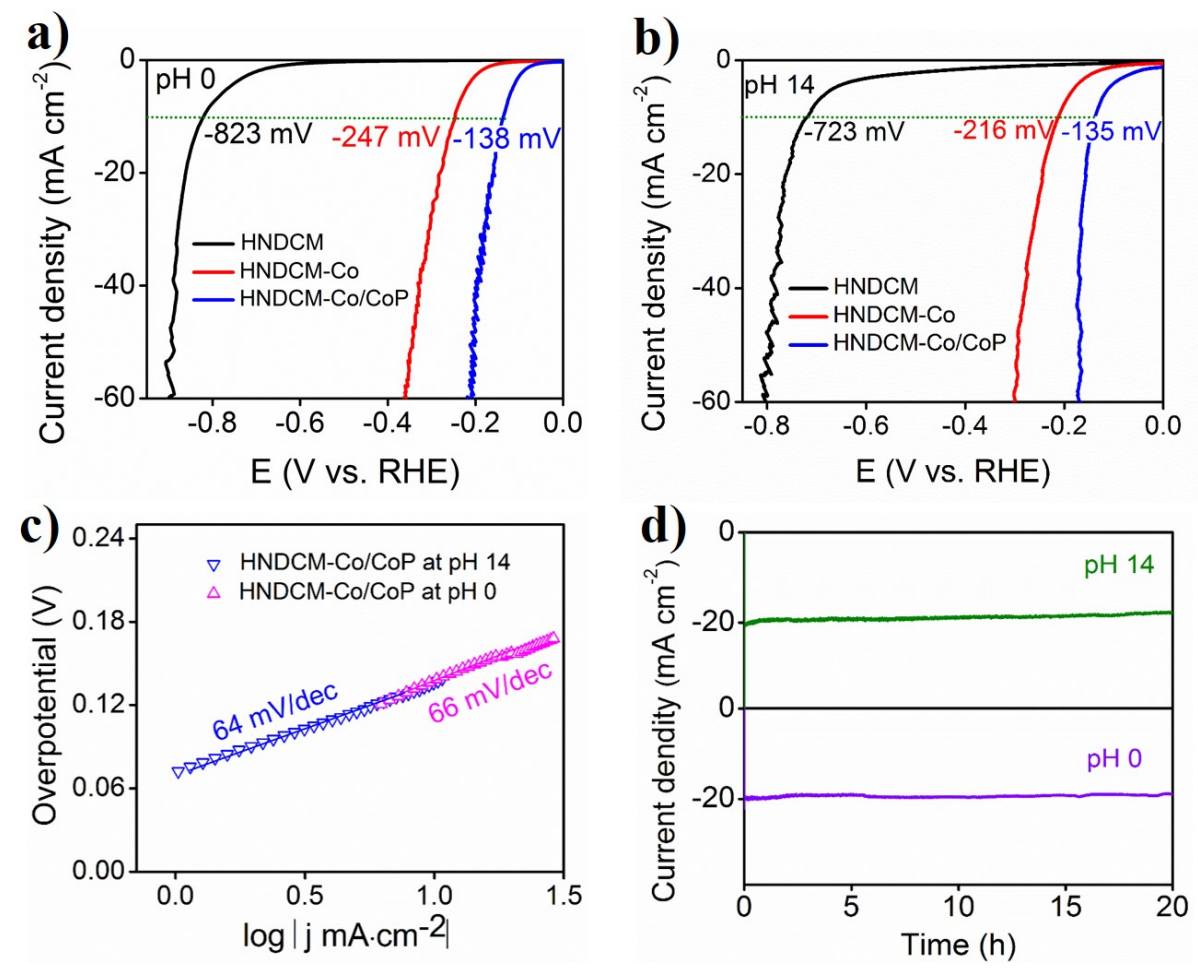

Figure 4. HER performances of HNDCM, HNDCM-Co and HNDCM-Co/CoP in (a) $0.5 \mathrm{M}$ $\mathrm{H}_{2} \mathrm{SO}_{4}$ and (b) $1 \mathrm{M} \mathrm{KOH.} \mathrm{(c)} \mathrm{Tafel} \mathrm{plots} \mathrm{of} \mathrm{HNDCM-Co/CoP} \mathrm{in} \mathrm{acid} \mathrm{and} \mathrm{alkaline} \mathrm{conditions.} \mathrm{(d)}$ Stability of HNDCM-Co/CoP in $0.5 \mathrm{M} \mathrm{H}_{2} \mathrm{SO}_{4}(\mathrm{pH}$ 0) and $1 \mathrm{M} \mathrm{KOH}(\mathrm{pH} 14)$.

As an important feature, our synthetic route towards freestanding membrane-type HER electrode can be easily scaled up. As a proof-of-concept demonstration for the solar-driven electrolysis of water, a large piece of HNDCM-Co/CoP of $5.6 \times 4 \mathrm{~cm}^{2}$ in size and $60 \mu \mathrm{m}$ in thickness (Figure 5) was prepared and driven by a solar panel (up to $20 \mathrm{~V}$ ) for HER in $1 \mathrm{M}$ $\mathrm{KOH}$, at an output voltage of non-regulated, fluctuating $20 \mathrm{~V}$. Such extreme and fluctuating conditions usually destroy conventional electrocatalytic materials in short times. It is also noted that this membrane was produced in a laboratory carbonization oven, but essentially any larger size can be made, given a corresponding carbonization technology. Figure 5 illustrates the HER 
operation within $10 \mathrm{~min}$, and $160 \mathrm{~mL} \mathrm{H}_{2}$ was collected, indicating the practicality of HNDCM$\mathrm{Co} / \mathrm{CoP}$ in simple, decentral $\mathrm{H}_{2}$ production in an environment-friendly manner.

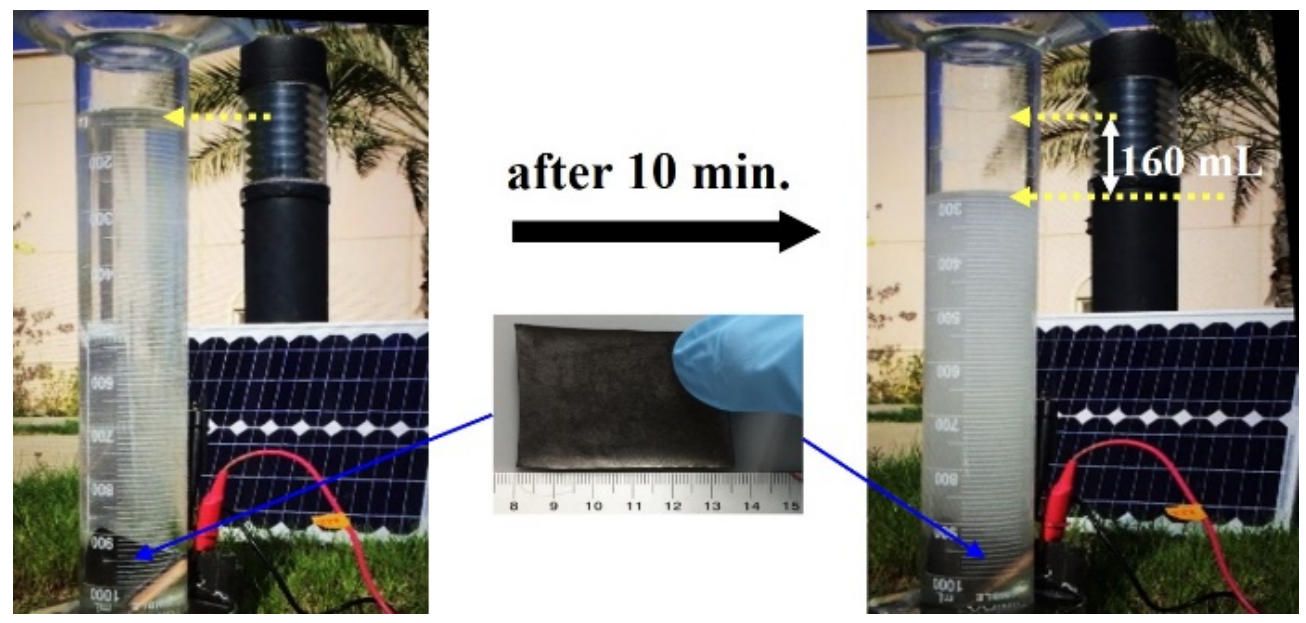

Figure 5. Illustration of HER driven by a solar panel in $1 \mathrm{M} \mathrm{KOH}$ with a piece of hybrid membrane $\mathrm{HNDCM}-\mathrm{Co} / \mathrm{CoP}$ with a size of $5.6 \mathrm{x} 4 \mathrm{~cm}^{2}$ and a thickness of $60 \mu \mathrm{m}$ as the working electrode, and the anode is a graphite electrode. In $10 \mathrm{~min}, 160 \mathrm{~mL}$ of $\mathrm{H}_{2}$ was released from the HNDCM-Co/CoP membrane.

\section{CONCLUSION}

In summary, we presented a general and scalable method to prepare N-doped, hierarchically structured porous graphitic carbon membranes with self-supported Janus-type Co/CoP nanocrystals, and HNDCM-Co/CoP serves as a highly active and robust earth-abundant electrode for hydrogen evolution reaction in both acid and alkaline conditions. Ease of large-scale preparation in combination with excellent electroactivity and remarkable long-term operation stability make HNDCM-Co/CoP promising for industrial-scale HER applications. Another unique feature of this genre of polyelectrolyte membrane is the ability to incorporate any type of metal ion and nanoparticle into the structure. As a unique feature of synthesis, metal nanoparticle functionalized HNCM membranes can be readily prepared by carbonization of a 
metal/polyelectrolyte membrane. We envision that $\mathrm{N}$-doped carbon membrane functionalized with different metal nanoparticles will provide myriad opportunities to develop highly efficient noble-metal-free electrocatalysts for power-to-fuel conversions in the current sustainable energy systems.

\section{METHODS}

Materials and Reagents. 1-Vinylimidazole (Aldrich 99\%), 2,2'-azobis(2-methylpropionitrile) (AIBN, 98\%), bromoace-tonitrile (Aldrich 97\%), and bis(trifluoromethanesulfonyl)imide lithium salt (LiTFSI, Aldrich 99\%) were used as received without further purifica-tions. Solvents of analytic grade were used as received. Poly(acrylic acid) (PAA) MW: 100,000 g/mol, $35 \mathrm{wt} \%$ in water, was obtained from Sigma Aldrich and used in a powder form after freeze-drying. The synthetic procedure of NPM was according to our previous method, ${ }^{48}$

Electrochemical Characterizations. The electrochemical measurements were performed with an electrochemical im-pedance spectroscopy (EIS) capable channel in a Biologic VMP3 potentiostat. A graphite rod and an $\mathrm{Ag} / \mathrm{AgCl}$ (in saturated $\mathrm{KCl}$ solution) electrode were used as the counter and reference electrodes, respectively. All the applied poten-tials are converted to reversible hydrogen electrode (RHE) potentials scale by using equation: E (vs. RHE) = E (vs. $\mathrm{Ag} / \mathrm{AgCl})+0.217 \mathrm{~V}+0.0591 \mathrm{~V} * \mathrm{pH}$, after IR correction. Potentiostatic EIS was used to determine the uncompensated solution resistance (Rs). The HER activity of HNDCM-Co/CoP was evaluated by measuring polarization curves with linear sweep voltammetry (LSV) technique at a scan rate of $1 \mathrm{mV} / \mathrm{s}$ in $1.0 \mathrm{M} \mathrm{KOH}(\mathrm{pH} 14)$ and $0.5 \mathrm{M} \mathrm{H}_{2} \mathrm{SO}_{4}(\mathrm{pH} 0)$ solutions. The stability tests for the $\mathrm{HNDCM}-\mathrm{Co} / \mathrm{CoP}$ were performed using chronoamperometry at a constant applied overpotential. 
Characterizations. X-ray diffraction (XRD) patterns were obtained using a Rigaku powder Xray diffractometer with $\mathrm{Cu} \mathrm{K \alpha}(\lambda=1.5418 \AA)$ radiation, $2 \theta$ angel was recorded from 20 to 80 degree. X-ray photoelectron spectroscopy (XPS) data were collected on an Axis Ultra instrument (Kratos Analytical) under ultrahigh vacuum $\left(<10^{-8}\right.$ Torr) using a monochromatic Al Ka X-ray source. The adventitious carbon peak was calibrated at $285 \mathrm{eV}$ and used as an internal standard to compensate for any charging effects. A field emission scanning electron microscope (FESEM, FEI Quanta 600FEG) was used to acquire SEM images. Transmission electron microscope (TEM) and high resolution TEM (HRTEM) images, selected-area electron diffraction (SAED) patterns, and the HAADF-STEM-EDS data were taken on a JEOL JEM-2100F transmission electron microscopy operated at $200 \mathrm{kV}$. Nitrogen sorption isotherms were measured at $-196{ }^{\circ} \mathrm{C}$ using a Micromeritics ASAP 2020M and 3020M system. The samples were degassed for $6 \mathrm{~h}$ at $200{ }^{\circ} \mathrm{C}$ before the measurements. STEM images were acquired in a probe-corrected JEOL ARM $200 \mathrm{~F}$, operated at $200 \mathrm{kV}$ and equipped with a cold field emission gun. Highangle annular dark field (HAADF) images were acquired with inner and outer collection angles of 50 and $180 \mathrm{mrad}$, respectively. Highresolution bright field (BF) images used $11 \mathrm{mrad}$ collection angles. Images were recorded with a dwell time of $20 \mathrm{~ms}$, and convergence semi-angle of $25 \mathrm{mrad}$, resulting in a probe current of $35 \mathrm{pA}$.

\section{ASSOCIATED CONTENT}

Supporting Information. SEM image of NPM; TEM image of HNDCM/Co/CoP; HRTEM image of $\mathrm{Co} / \mathrm{CoP}$ Janus nanocrystal; HRTEM image of graphtic $\mathrm{N}$-doped carbon; Temperature dependence of conductivity of HNDCM-Co/CoP; XRD patterns of HNDCM-Co and HNDCM$\mathrm{Co} / \mathrm{CoP}$; XPS spectrum of HNDCM-Co/CoP; Table S1 for comparison the performance of 
different electrocatalysts (PDF). This material is available free of charge via the Internet at http://pubs.acs.org.

\section{Corresponding Authors}

jiayin.yuan@mpikg.mpg.de;

tao.wu@kaust.edu.sa

\section{Author Contributions}

$\$$ These authors contributed equally.

\section{Notes}

The authors declare no competing financial interest

\section{ACKNOWLEDGMENT}

H. W. and T. W. thank the King Abdullah University of Science and Technology (KAUST) for financial support. S. M acknowledges the financial support from the National Natural Science Foundation of China (21463001). J. Y. is grateful for financial support from the Max Planck society, Germany, and the ERC (European Research Council) Starting Grant (project number 639720-NAPOLI). This research used equipment funded by the Australian Research Council (ARC) - Linkage, Infrastructure, Equipment and Facilities (LIEF) grant LE120100104 located at the UOW Electron Microscopy Centre.

\section{REFERENCES}

(1) Turner, J. A. Sustainable Hydrogen Production. Science 2004, 305, 972-974. 
(2) Lu, Q.; Yu, Y.; Ma, Q. Chen, B.; Zhang, H. 2D Transition-Metal-Dichalcogenide-

Nanosheet-Based Composites for Photocatalytic and Electrocatalytic Hydrogen Evolution

Reactions. Adv. Mater. 2016, 28, 1917-1933.

(3) Chen, J.; Wu, X.-J.; Yin, L.; Li, B.; Hong, X.; Fan, Z.; Chen, B.; Xue, C. Zhang, H. One-pot

Synthesis of CdS Nanocrystals Hybridized with Single-LayeTransition-Metal Dichalcogenide

Nanosheets for Efficient Photocatalytic Hydrogen Evolution. Angew. Chem. Int. Ed. 2015, 54,

$1210-1214$.

(4) Nocera, D. G. The Artificial Leaf. Acc. Chem. Res. 2012, 45, 767-776.

(5) Duan, J.; Chen, S.; Vasileff, A.; Qiao, S. Z. Anion and Cation Modulation in Metal

Compounds for Bifunctional Overall Water Splitting, ACS Nano, 2016, 10, 8738-8745.

(6) Walter, M. G.; Warren, E. L.; McKone, J. R.; Boettcher, S. W.; Mi, Q.; Santori, E. A.; Lewis,

N. S. Solar Water Splitting Cells. Chem. Rev. 2010, 110, 6446-6473.

(7) Popczun, E. J.; McKone, J. R.; Read, C. G.; Biacchi, A. J.; Wiltrout, A. M.; Lewis, N.S.;

Schaak, R. E. Nanostructured Nickel Phosphide as An Electrocatalyst for the Hydrogen

Evolution Reaction. J. Am. Chem. Soc. 2013, 135, 9267-9270.

(8) Wan, C.; Regmi, Y. N.; Leonard, B. M. Multiple Phases of Molybdenum Carbide as

Electrocatalysts for the Hydrogen Evolution Reaction. Angew. Chem., Int. Ed. 2014, 126, 65256528.

(9) Jin, H.; Wang, J.; Su, D.; Wei, Z.; Pang, Z.; Wang, Y. In situ Cobalt-Cobalt Oxide/N-doped Carbon Hybrids as Superior Bifunctional Electrocatalysts for Hydrogen and Oxygen Evolution $J$. Am. Chem. Soc. 2015, 137, 2688- 2694. 
(10) Cabán-Acevedo, M.; Stone, M. L.; Schmidt, J. R.; Thomas, J. G.; Ding, Q.; Chang, H.-C.;

Tsai, M. L.; He, J.-H.; Jin, S. Efficient Hydrogen Evolution Catalysis Using Ternary Pyrite-Type Cobalt Phosphosulphide. Nat. Mater. 2015, 14, 1245-1251.

(11) Yang, Y.; Fei, H.; Ruan, G.; Xiang, C.; Tour, J. M. Edge Oriented $\mathrm{MoS}_{2}$ Nanoporous Films as Flexible Electrodes for Hydrogen Evolution Reactions and Supercapacitor Devices. Adv. Mater. 2014, 26, 8163-8168.

(12) Huang, X.; Zeng, Z.; Bao, S.; Wang, M.; Qi, X. Fan, Z.; Zhang H.; Solution-Phase Epitaxial Growth of Noble Metal Nanostructures on Dispersible Single-Layer Molybdenum Disulfide Nanosheets. Nat. Commun., 2013, 4, 1444.

(13) Ma, C.-B.; Qi, X.; Chen, B.; Bao, S.; Yin, Z.; Wu, X.-J.; Luo, Z.; Wei, J.; Zhang, H.-L. Zhang H. $\mathrm{MoS}_{2}$ Nanoflower-Decorated Reduced Graphene Oxide Paper for High-Performance Hydrogen Evolution Reaction. Nanoscale, 2014, 6, 5624-5629

(14) Liu, Q.; Tian, J.; Cui, W.; Jiang, P.; Cheng, N.; Asiri, A. M.; Sun, X. Carbon Nanotubes Decorated with CoP Nanocrystals: A Highly Active Non Noble Metal Nanohybrid Electrocatalyst for Hydrogen Evolution. Angew. Chem., Int. Ed. 2014, 126, 6828-6832. (15) Miao, J.; Xiao, F.-X.; Yang, H. B.; Khoo, S. Y.; Chen, J.; Fan, Z.; Hsu, Y.-Y.; Chen, H. M.; Zhang, H.; Liu, B. Hierarchical Ni-Mo-S Nanosheets on Carbon Fiber Cloth: A Flexible Electrode for Efficient Hydrogen Generation in Neutral Electrolyte. Sci. Adv., 2015, 1 , e1500259.

(16) Liu, Y.; Hua, X.; Xiao, C.; Zhou, T.; Huang, P.; Guo, Z.; Pan, B.; Xie, Y. Heterogeneous Spin States in Ultrathin Nanosheets Induce Subtle Lattice Distortion to Trigger Efficient Hydrogen Evolution. J. Am. Chem. Soc. 2016, 138, 5087-5092. 
(17) Kong, D.; Wang, H.; Lu, Z.; Cui, Y. CoSe ${ }_{2}$ Nanoparticles Grown on Carbon Fiber Paper: an Efficient and Stable Electrocatalyst for Hydrogen Evolution Reaction. J. Am. Chem. Soc. 2014, $136,4897-4900$.

(18) Liang, H. W.; Bruller, S.; Dong, R. H.; Zhang, J.; Feng, X. L.; Mülllen, K. Molecular MetalNx Centres in Porous Carbon for Electrocatalytic Hydrogen Evolution. Nat. Commun. 2015, 6, 7992.

(19) Zhao, M.-Q.; Ren, C. E., Ling, Z.; Lukatskaya, M. R.; Zhang, C.; Aken, K. L. V.;

Barsoum, M. W.; Gogotsi Y. Flexible MXene/Carbon Nanotube Composite Paper with High Volumetric Capacitance. Adv. Mater. 2015, 27, 339-345.

(20) Zheng, Y.; Jiao, Y.; Qiao, S. Z. Engineering of Carbon-Based Electrocatalysts for Emerging Energy Conversion: From Fundamentality to Functionality. Adv. Mater. 2015, 27, 5372-5378.

(21) Fan, X.; Peng, Z.; Ye, R.; Zhou, H.; Guo, X. Mㄱ (M: Fe, Co, Ni) Nanocrystals Encased in Graphene Nanoribbons: An Active and Stable Bifunctional Electrocatalyst for Oxygen Reduction and Hydrogen Evolution. ACS Nano 2015, 9, 7407-7418.

(22) Jiao, Y.; Zheng, Y.; Davey, K.; Qiao, S.-Z. Activity Origin and Catalyst Design Principles for Electrocatalytic Hydrogen Evolution on Heteroatom-doped Graphene. Nat. Energy 2016, 1, 16130.

(23) Duan, J. Chen, S.; Chambers, B. A.; Andersson, G. G.; Qiao, S. Z. 3D WS

Nanolayers@Heteroatom-Doped Graphene Films as Hydrogen Evolution Catalyst Electrodes. Adv. Mater. 2015, 27, 4234-424.

(24) Gogotsi, Yu. G. Carbon nanomaterials, CRC Press: Boca Raton, FL, 2006; Chapter 1. 
(25) Chen, S.; Duan, J.; Tang, Y.; Jin, B.; Qiao, S. Z. Molybdenum Sulfide Clusters-NitrogenDoped Graphene Hybrid Hydrogel Film as an Efficient Three-Dimensional Hydrogen Evolution Electrocatalyst. Nano Energy 2015, 11, 11-18.

(26) Wang, Y.; Gong, M.; Chou, H.-L.; Pan, C.-J.; Chen, H.-A.; Wu, Y.; Lin, M.-C.; Guan, M.; Yang, J.; Chen, C.-W.; Wang, Y.-L.; Hwang, B.-J.; Chen, C.-C.; Dai, H. Highly Active and Stable Hybrid Catalyst of Cobalt-Doped $\mathrm{FeS}_{2}$ Nanosheets-Carbon Nanotubes for Hydrogen Evolution Reaction. J. Am. Chem. Soc. 2015, 137, 1587-1592.

(27) Bayatsarmadi, B.; Zheng, Y.; Tang, Y.; Jaroniec, M.; Qiao, S.-Z. Significant Enhancement of Water Splitting Activity of N-Carbon Electrocatalyst by Trace Level Co Doping. Small 2016, $12,3703-3711$.

(28) Black, R.; Oh, S. H.; Lee, J.-H.; Yim, T.; Adams, B.; Nazar, L. F. Screening for Superoxide Reactivity in Li- $\mathrm{O}_{2}$ Batteries: Effect on $\mathrm{Li}_{2} \mathrm{O}_{2} / \mathrm{LiOH}$ Crystallization. J. Am. Chem. Soc. 2012, $134,2902-2905$.

(29) Wang, H.; Min, S.; Ma, C.; Liu, Z.; Zhang, W.; Wang, Q.; Li, D.; Li, Y.; Turner, S.; Han, Y.; Zhu, H.; Abou-hamad, E.; Hedhili, M. N.; Pan, J.; Yu, W. ; Huang, K.-W.; Li, L.-J.; Yuan, J.; Antonietti, M.; Wu, T. Synthesis of Single-Crystal-like Nanoporous Carbon Membranes and Their Application in Overall Water Splitting. Nat. Commun. 2017, 8, 13592.

(30) Li, D.; Maiti, U. N.; Lim, J.; Choi, D. S.; Lee, W. J.; Oh,Y.; Lee, G.; Kim, S. O. Molybdenum Sulfide/N-Doped CNT Forest Hybrid Catalysts for High-Performance Hydrogen Evolution Reaction. Nano Lett. 2014, 14, 1228-1233.

(31) Duan, J.; Chen, S.; Jaroniec, M.; Qiao, S. Z. Heteroatom-Doped Graphene-Based Materials for Energy-Relevant Electrocatalytic Processes. ACS Catal., 2015, 5, 5207-5234. 
(32) Popczun, E. J.; Read, C. G.; Roske, C. W.; Lewis, N. S.; Schaak, R. E. Highly Active

Electrocatalysis of the Hydrogen Evolution Reaction by Cobalt Phosphide Nanoparticles. Angew.

Chem., Int. Ed. 2014, 126, 5531-5534.

(33) Fei, H.; Dong, J.; Arellano-Jimenez, M. J.; Ye, G.; Dong Kim, N.; Samuel, E. L.; Peng, Z.;

Zhu, Z.; Qin, F.; Bao, J.; Yaca-man, M. J.; Ajayan, P. M.; Chen, D.; Tour, J. M. Atomic Cobalt

on Nitrogen-Doped Graphene for Hydrogen Generation. Nat. Commun. 2015, 6, 8668.

(34) Zeng, K.; Zhang, D. Prog. Recent Progress in Alkaline Water Electrolysis for Hydrogen

Production and Applications. Energy Combust. Sci. 2010, 36, 307-326.

(35) Hall, D. E. Electrodes for alkaline water electrolysis. J. Electrochem. Soc. 1981, 128, 740-

746.

(36) Schrinner, M.; Ballauff, M.; Talmon, Y.; Kauffmann, Y.; Thun, J.; Moeller, M.; Breu, J. Single Nanocrystals of Platinum Prepared by Partial Dissolution of Au-Pt Nanoalloys. Science 2009, 323, 617-620.

(37) Zheng, Y.; Jiao, Y.; Jaroniec, M.; Qiao, S. Z. Advancing the Electrochemistry of the Hydrogen Evolution Reaction through Combining Experiment and Theory. Angew. Chem., Int. Ed. 2015, 54, 52-65.

(38) Gong, J.; Lin, H.; Antonietti, M.; Yuan, J. Nitrogen-Doped Porous Carbon Nanosheets Derived from Poly (ionic liquid)s: Hierarchical Pore Structures for Efficient $\mathrm{CO}_{2}$ Capture and Dye Removal. J. Mater. Chem. A, 2016, 4, 7313-7321.

(39) Li, X.-H.; Antonietti, M. Metal nanoparticles at Mesoporous N-doped Carbons and Carbon Nitrides: Functional Mott-Schottky Heterojunctions for Catalysis. Chem. Soc. Rev., 2013, 42, 6593-6604. 
(40) Ledendecker, M.; Calderón, S. K.; C. Papp, Steinrück, H.-P.; Antonietti, M.; Shalom, M.

The Synthesis of Nanostructured $\mathrm{Ni}_{5} \mathrm{P}_{4}$ Films and their Use as a Non-Noble Bifunctional

Electrocatalyst for Full Water Splitting. Angew. Chem., Int. Ed. 2015, 127, 12538-12542.

(41) Ledendecker, M.; Clavel, G.; Antonietti, M.; Shalom, M. Highly Porous Materials as

Tunable Electrocatalysts for the Hydrogen and Oxygen Evolution Reaction. Adv. Funct. Mater.

2015, 25, 393-399.

(42) Yin, J.; Fan, Q.; Li, Y.; Cheng, F.; Zhou, P.; Xi, P.; Sun, S. Ni-C-N Nanosheets as Catalyst for Hydrogen Evolution Reaction. J. Am. Chem. Soc. 2016, 138, 14546-14549.

(43) Zheng, Y.; Jiao, Y.; Zhu,Y.; Li, L. H.; Han,Y.; Chen, Y.; Jaroniec, M.; Qiao, S.-Z. High Electrocatalytic Hydrogen Evolution Activity of an Anomalous Ruthenium Catalyst. J. Am.

Chem. Soc., 2016, 138, 16174-16181.

(44) Yin, H.; Zhao, S.; Zhao, K.; Muqsit, A.; Tang, H.; Chang, L.; Zhao, H.; Gao, Y.; Tang, Z.

Ultrathin Platinum Nanowires Grown on Single-Layered Nickel Hydroxide with High Hydrogen Evolution Activity. Nat. Commun. 2015, 6, 6430.

(45) Conway, B. E.; Tilak, B. V. Interfacial Processes Involving Electrocatalytic Evolution and Oxidation of $\mathrm{H}_{2}$, and the Role of Chemisorbed H. Electrochim. Acta 2002, 47, 3571-3594.

(46) Zitolo, A.; Goellner, V.; Armel, V.; Sougrati, M.-T.; Mineva, T.; Stievano, L.; Fonda, E.;

Jaouen, F. Identification of Catalytic Sites for Oxygen Reduction in Iron-and Nitrogen-Doped Graphene materials. Nat. Mater. 2015, 14, 937-942.

(47) Fellinger, T.-P.; Thomas, A.; Yuan, J.; Antonietti, M. 25th Anniversary Article: “Cooking Carbon with Salt”: Carbon Materials and Carbonaceous Frameworks from Ionic Liquids and Poly(ionic liquid)s. Adv. Mater. 2013, 25, 5838-5855. 
(48) Zhao, Q.; Yin, M.; Zhang, A. P.; Prescher, S.; Antonietti, M.; Yuan, J. Hierarchically

Structured Nanoporous Poly (ionic liquid) Membranes: Facile Preparation and Application in

Fiber-Optic pH Sensing. J. Am. Chem. Soc.2013, 135, 5549-5552.

\section{TOC Figure}

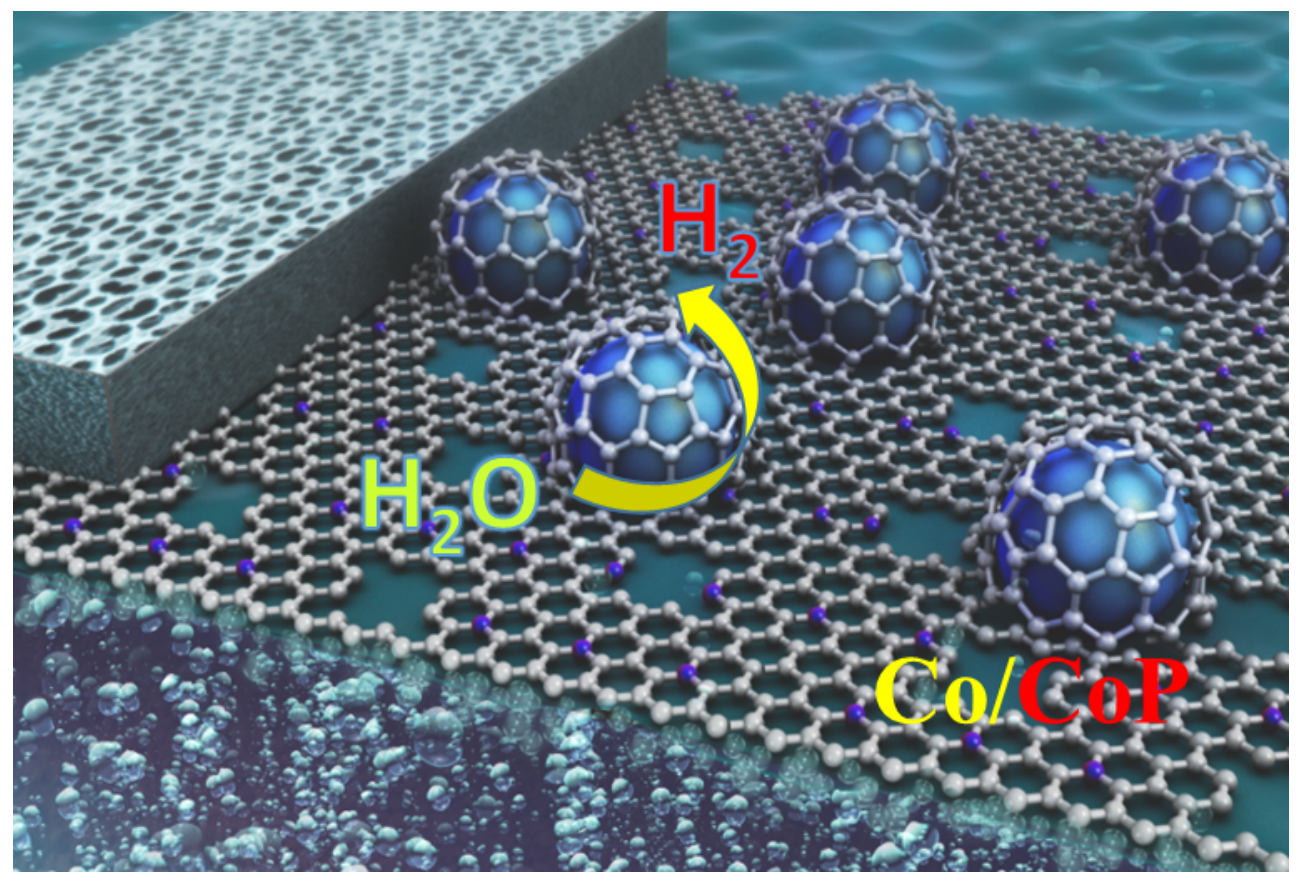

